\title{
Synthesis, structure and characterization of a new cadmium(II) iodide containing a tetradentate tripodal amine
}

\author{
Kamel Kaabi ${ }^{\mathrm{a}}$, Valeria Ferretti ${ }^{\mathrm{b}}$, Frédéric Lefebvre ${ }^{\mathrm{c}}$, Chérif Ben Nasr ${ }^{\mathrm{a} *}$
}

a Laboratoire de Chimie des Matériaux, Faculté des Sciences de Bizerte, 7021 Zarzouna, Tunisie,

${ }^{\mathrm{b}}$ Department of Chemical and Pharmaceutical Sciences and Center for Structural Diffractometry, via Fossato di Mortara 17, I-44121 Ferrara, Italy

${ }^{\mathrm{c}}$ Laboratoire de Chimie Organometallique de Surface (LCOMS), Ecole Supérieure de Chimie Physique Electronique, 69622 Villeurbanne Cedex, France.

*Corresponding author: cherif_bennasr@yahoo.fr

\section{ABSTRACT}

A cadmium(II) iodide compound of the $[\mathrm{Cd}(\mathrm{L}) \mathrm{I}] \mathrm{l}$ series, with $\mathrm{L}=$ tris(2-aminoethyl)amine, is synthesized and characterized. X-ray structural study shows that the title compound has a slightly distorted trigonal bipyramidal environment where the $\mathrm{CdN}_{4} \mathrm{l}$ chromophore is bounded by $\mathrm{N}$ atoms of $\mathrm{L}$ and one iodide. In the structural arrangement, the $\left[\mathrm{Cd}(\mathrm{L}) \mathrm{I}^{+}\right.$cationic complexes are interconnected via $\mathrm{N}-\mathrm{H} \ldots \mathrm{I}$ hydrogen bonds generated by the uncoordinated I iodide anions to form layers parallel to the $(\mathrm{a}, \mathrm{c})$ plane. The ${ }^{13} \mathrm{C}$ CP-MAS NMR spectrum is discussed and the vibrational absorption bands were identified by infrared spectroscopy and DFT calculations.

\section{Indexing terms/Keywords}

Cadmium(II) iodide compound ; Tripodal amine ; X-ray structure ; CP-MAS NMR ; DTF calculations

\section{Council for Innovative Research}

Peer Review Research Publishing System

Journal: Journal of Advances in Chemistry

Vol. 10, No. 5

editorjaconline@gmail.com

www.cirjac.com 


\section{INTRODUCTION}

The last decade has witnessed an enormous effect in $\mathrm{Cd}(\mathrm{II})$ coordination polymers, which display variety of metal-organic

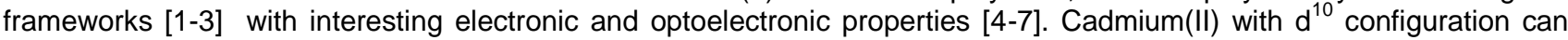
adopt a variety of coordination geometries, which can range within tetrahedral, trigonal bipyramidal, square pyramidal and octahedral and are particularly useful for the construction of coordination frameworks [8]. On the other hand, hydrogen bonding plays a crucial role in the construction of coordination polymers [9]. Combination of both metal-ligand covalent bonding and hydrogen bonding in designing the coordination polymers has been considered as an attractive design strategy because of the possibility of structural variations and guest entrapment induced by specific hydrogen bonding interactions. Polyamines, heterocycles and Schiff bases are important chelating ligands in the preparation of coordination compounds [10-12]. In our present work, we have chosen a tetradentate tripodal amine, tris(2-aminoethyl)amine (L), to isolate a mononuclear cadmium(II) iodide material which contains a pentacoordinated metal ion. It is worth noticing that Satapathi et al. [13] have reported a binuclear cadmium(II) iodide with the same ligand comprising two cadmium(II) centers, with one trigonal bipyramidal geomerty and the other with $T_{d}$ environment, whereas one iodide ion bridges the two metal centers.

\section{Experiment}

\subsection{Chemical preparation}

A solution of $\mathrm{Cdl}_{2}(36.7 \mathrm{mg}, 0.1 \mathrm{mmol})$ in water was added dropwise to a solution of Tris(2-aminoethyl)amine $(14.7 \mathrm{mg}, 0.1 \mathrm{mmol})$ in ethanol. After stirring for $30 \mathrm{~min}$, the mixture was filtered. Crystals suitable for X-ray analysis, which remained stable under normal conditions of temperature and humidity, were isolated after several days by evaporating the filtrate at room temperature (yield 58\%).

\subsection{Investigation techniques}

The characterization of the title compound was carried out by X-ray diffraction, solid state NMR, DFT calculations, and IR spectroscopy.

\subsubsection{X-ray single crystal structural analysis}

The crystallographic data for the title compound were collected on a Nonius Kappa CCD diffractometer at room temperature using graphite-monochromated MoKa radiation $(\lambda=0.71073 \AA$ ). Data sets were integrated with the DenzoSMN package [14] and corrected for Lorentz-polarization and absorption [15] effects. The crystal parameters and other experimental details of the data collection are summarized in Table 1. The structure was solved by direct methods with the SIR97 suite of programs [16] and refinement was performed on $F^{2}$ by full-matrix least-squares methods with all nonhydrogen atoms anisotropic. Hydrogen atoms were included on calculated positions, riding on their carrier atoms. All calculations were performed using SHELXL-97 [17] implemented in the WINGX system of programs [18]. Selected bond distances are given in Table 2. The ORTEPIII [19] diagram is shown in Figure 1. The other drawings were made with Diamond [20].

\subsubsection{Physical measurements}

The ${ }^{13} \mathrm{C}$ NMR spectrum was recorded on a solid-state high-resolution Bruker DSX-300 spectrometer operating at $75.49 \mathrm{MHz}$ with a classical $4 \mathrm{~mm}$ probehead allowing spinning rates up to $10 \mathrm{kHz}$. The NMR chemical shifts are given relative to tetramethylsilane (precision $0.5 \mathrm{ppm}$ ). The spectrum was recorded by use of cross-polarization (CP) from protons (contact time $5 \mathrm{~ms}$ ) and MAS. Before recording the spectrum it was checked that there was a sufficient delay between the scans allowing a full relaxation of the protons (typically $10 \mathrm{~s}$ ). The IR spectrum was recorded in the range $4000-400 \mathrm{~cm}^{-1}$ on a "Nicolet 6700 " spectrophotometer (resolution $=2 \mathrm{~cm}^{-1}$, number of scans $=256$ ).

\subsubsection{DFT calculations}

The calculations were made with the Gaussian A.09 software by use of the B3LYP method. The basis set was 6 $31+G^{*}$ for all atoms except for $\mathrm{Cd}$ and I for which the LanL2DZ pseudopotential was used. Three types of calculations were made (see below) and in each case both the NMR chemical shifts and the IR spectrum were calculated. 
Table 1. Crystal data and refinement parameters of [CdI $\left.\left(\mathrm{C}_{6} \mathrm{H}_{18} \mathrm{~N}_{4}\right)\right]$.

\section{Crystal data}

Chemical formula

$M_{\mathrm{r}}$

Crystal system, space group

$a, b, c(\stackrel{\mathrm{A}}{)}$

$\beta\left(^{\circ}\right)$

$V\left(\AA^{3}\right)$

$Z$

$\mu\left(\mathrm{mm}^{-1}\right)$

Crystal size (mm)

No. of measured, independent and observed reflections $[I>2 \sigma(I)]$

$R_{\text {int }}$

$R\left[\digamma^{2}>2 \sigma\left(\digamma^{\dot{2}}\right)\right], w R\left(\digamma^{2}\right), S$

No. of reflections

No. of parameters

$\Delta \rho_{\max }, \Delta \rho_{\min }\left(\mathrm{e} \check{A}^{-3}\right)$
$\mathrm{C}_{6} \mathrm{H}_{18} \mathrm{CdIN}_{4} \mathrm{I}$

512.44

Monoclinic, $P 2_{1} / C$

7.8508 (2), 16.6358 (3), 11.0386 (3)

$95.1790(8)$

$1435.80(6)$

4

5.79

$0.35 \times 0.18 \times 0.09$

20238, 3465, 2657

0.077

$0.044,0.121,1.06$

3465

119

$1.75,-1.47$

\section{Results and discussion}

\subsection{X-ray diffraction study}

The asymmetric unit of the title compound consists of a Cd(II) cationic complex and its iodide counterion. The $\mathrm{Cd}(\mathrm{II})$ ion is pentacoordinated by four nitrogen atoms (N1, N2, N3 and N4) of the tetradentate tris(2-aminoethyl)amine (L) $\mathrm{L}$ ligand and one iodide anion I1 to give a trigonal bipyramidal coordination geometry; the presence of a bulky iodide ligand may be one of the major reasons that enforce lower coordination of this large-sized $4 \mathrm{~d}$ ion. The degree of distortion from a regular trigonal bipyramid can be quantified by the structural index $\tau$, namely the Addison parameter $\tau=(\beta-\alpha) / 60$ with $\alpha$ and $\beta$ being the two largest angles, which assumes the value of zero for an ideal square pyramidal and becomes equal to one for an ideal trigonal bipyramid [21]; the calculated $\tau$ values of the title compound is $\tau(\mathrm{Cd})=0.97$ (where $\beta$ and $\alpha$ values are 176.1(1) and $117.9(2)^{\circ}$, respectively), indicating a quite small distortion from the regular polyhedron. For the sake of comparison, nine pentacoordinated Cd complexes containing the $L$ ligand have been retrieved from CSD [13, 22 27]; for them, the $\tau(\mathrm{Cd})$ values are in the range $0.64-0.95$. The geometrical parameters of the $\mathrm{CdN}_{4}$ l chromophore (Table 2) are in agreement with those of the literature compounds, being their mean Cd-N distances $2.419 \AA$ (for $\mathrm{Cd}-\mathrm{N} 1)$ and $2.292 \AA$ (for the other $\mathrm{Cd}-\mathrm{N}$ bonds). The bond valence calculation gives a value of 2.00 for the $\mathrm{Cd}$ (II) cation [28] .

In the crystal, the free anion $\mathrm{I} 2$ links three complexes acting as a hydrogen bond acceptor towards three $\mathrm{NH}_{2}$ groups (Table 3 and Fig. 2); this generates puckered layers almost parallel to the (a, c) plane (Fig. 2). The layers are in turn interacting through van der Waals interactions. 
Table2. Selected bond distances and angles $(\stackrel{\AA}{4}, \stackrel{\circ}{)})$ in $\left[\mathrm{Cdl}\left(\mathrm{C}_{6} \mathrm{H}_{18} \mathrm{~N}_{4}\right)\right]$.

\begin{tabular}{|llll|}
\hline Cd1-N3 & $2.289(5)$ & $\mathrm{N} 3-\mathrm{Cd} 1-\mathrm{N} 1$ & $75.1(2)$ \\
$\mathrm{Cd} 1-\mathrm{N} 2$ & $2.293(5)$ & $\mathrm{N} 2-\mathrm{Cd} 1-\mathrm{N} 1$ & $75.4(2)$ \\
$\mathrm{Cd} 1-\mathrm{N} 4$ & $2.297(5)$ & $\mathrm{N} 4-\mathrm{Cd} 1-\mathrm{N} 1$ & $75.3(2)$ \\
$\mathrm{Cd} 1-\mathrm{N} 1$ & $2.448(5)$ & $\mathrm{N} 3-\mathrm{Cd} 1-\mathrm{I} 1$ & $107.9(1)$ \\
$\mathrm{Cd} 1-\mathrm{I} 1$ & $2.7661(6)$ & $\mathrm{N} 2-\mathrm{Cd} 1-\mathrm{I} 1$ & $104.8(1)$ \\
$\mathrm{N} 3-\mathrm{Cd} 1-\mathrm{N} 2$ & $117.9(2)$ & $\mathrm{N} 4-\mathrm{Cd} 1-\mathrm{I} 1$ & $101.1(2)$ \\
$\mathrm{N} 3-\mathrm{Cd} 1-\mathrm{N} 4$ & $111.2(2)$ & $\mathrm{N} 1-\mathrm{Cd} 1-\mathrm{I} 1$ & $176.1(1)$ \\
$\mathrm{N} 2-\mathrm{Cd} 1-\mathrm{N} 4$ & $112.2(2)$ & & \\
\hline
\end{tabular}

Table 3. Hydrogen-bond geometry $\left(\AA \stackrel{\AA}{\circ} \stackrel{\circ}{)}\right.$ in $\left[\mathrm{Cdl}\left(\mathrm{C}_{6} \mathrm{H}_{18} \mathrm{~N}_{4}\right)\right]$.

\begin{tabular}{|c|c|c|c|c|}
\hline $\mathrm{D}-\mathrm{H} \cdots \mathrm{A}$ & $\mathrm{D}-\mathrm{H}$ & $H \cdots A$ & $D \cdots A$ & $\mathrm{D}-\mathrm{H} \cdots \mathrm{A}$ \\
\hline N3-H...I2 & 0.90 & 2.99 & $3.749(6)$ & 143 \\
\hline N4-H...I2' & 0.90 & 2.83 & $3.709(6)$ & 165 \\
\hline $\mathrm{N} 4-\mathrm{H} . . .12^{\prime \prime}$ & 0.90 & 2.92 & $3.716(6)$ & 149 \\
\hline
\end{tabular}

Symmetry codes: (i) $x-1, y, z$; (ii) $x-1,1 / 2-y, z-1 / 2$.

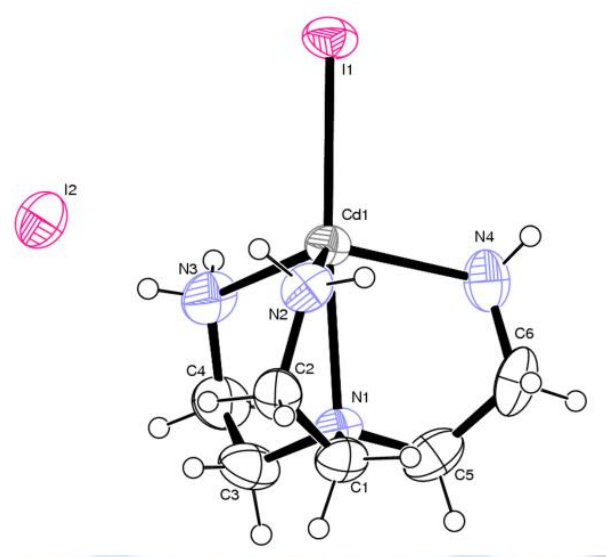

Figure 1. Asymmetric unit of $\left[\mathrm{Cdl}\left(\mathrm{C}_{6} \mathrm{H}_{18} \mathrm{~N}_{4}\right)\right]$ with the atom numbering scheme and thermal ellipsoids at $40 \%$ probability. 


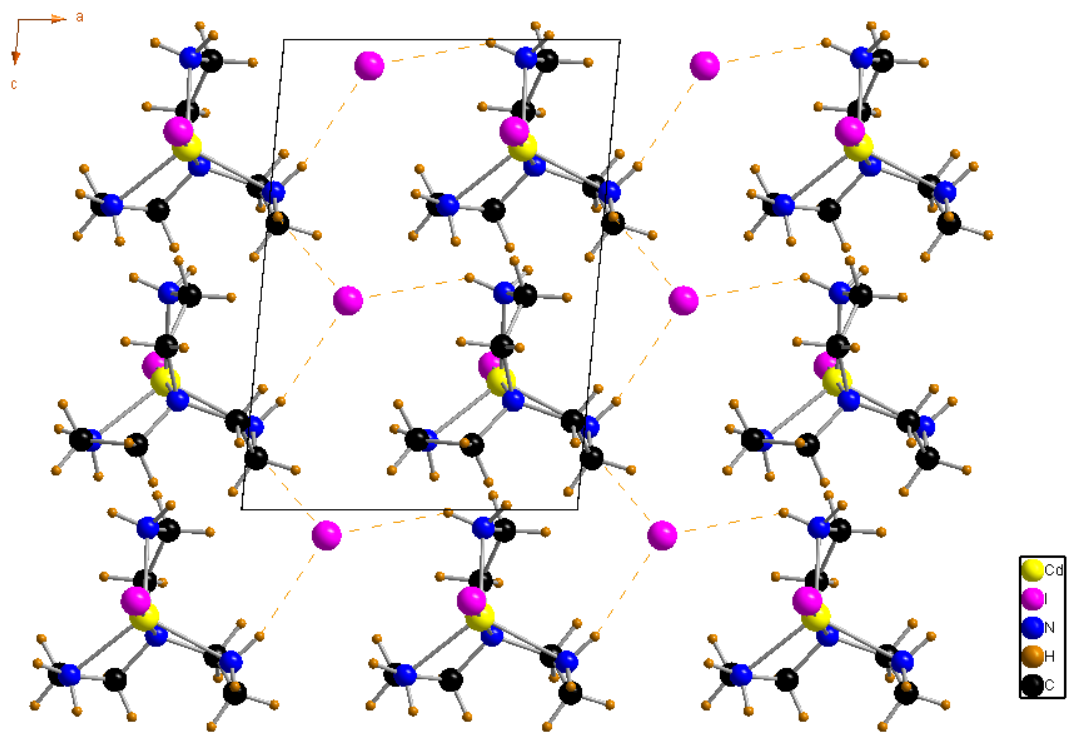

Figure 2. Projection along the $b$-axis of a puckered layer in $\left[\mathrm{CdI}\left(\mathrm{C}_{6} \mathrm{H}_{18} \mathrm{~N}_{4}\right)\right]$. The dotted lines indicate hydrogen

\subsection{Solid state NMR spectroscopy}

The ${ }^{13} \mathrm{C}$ CP-MAS NMR spectrum of $[\mathrm{Cd}(\mathrm{L}) \mathrm{I}] \mathrm{I}$ is shown in Fig. 3. It exhibits five resonances corresponding to the six crystallographically independent carbon atoms, with one of the peaks, at $37.4 \mathrm{ppm}$, having an intensity about the double of the other four resonances. The spectrum can thus be interpreted as featuring six resonances, with two of them in close proximity with substantial overlap. This is in agreement with only one organic molecule being present in the asymmetric unit cell as revealed by $\mathrm{X}$-ray structure determination.

Theoretical calculations were undertaken in order to assign the NMR resonances to the different crystallographically unequivalent carbon atoms of the unit cell. Three different calculations were made on the organic cation and in all cases the theoretical chemical shifts were subtracted from those of the reference (tetramethylsilane) calculated at the same level of theory:

(1) Calculation of the NMR chemical shifts (with the GIAO method) by using the positions of atoms obtained by $\mathrm{X}$ ray diffraction;

(2) Optimization of the positions of the protons in the above molecule and calculation of the NMR chemical shifts in this semi-optimized geometry. Indeed X-ray diffraction leads always to underestimated X-H bond lengths, due to the fact that it is sensitive to the electronic cloud and does not see the nuclei;

(3) Full optimization of all atoms and calculation of NMR chemical shifts. This calculation, compared to the above one will give indications on the steric hindrance around the organic cation and on the positions where it is the strongest. 
The results are listed in Table 4, while Figure 4 shows the correlation between experimental and calculated values (after optimization of the protons positions). Clearly, there is a good agreement between the experimental and theoretical values calculated after optimization of the position of the protons, allowing unambiguously the attribution of the different NMR signals.

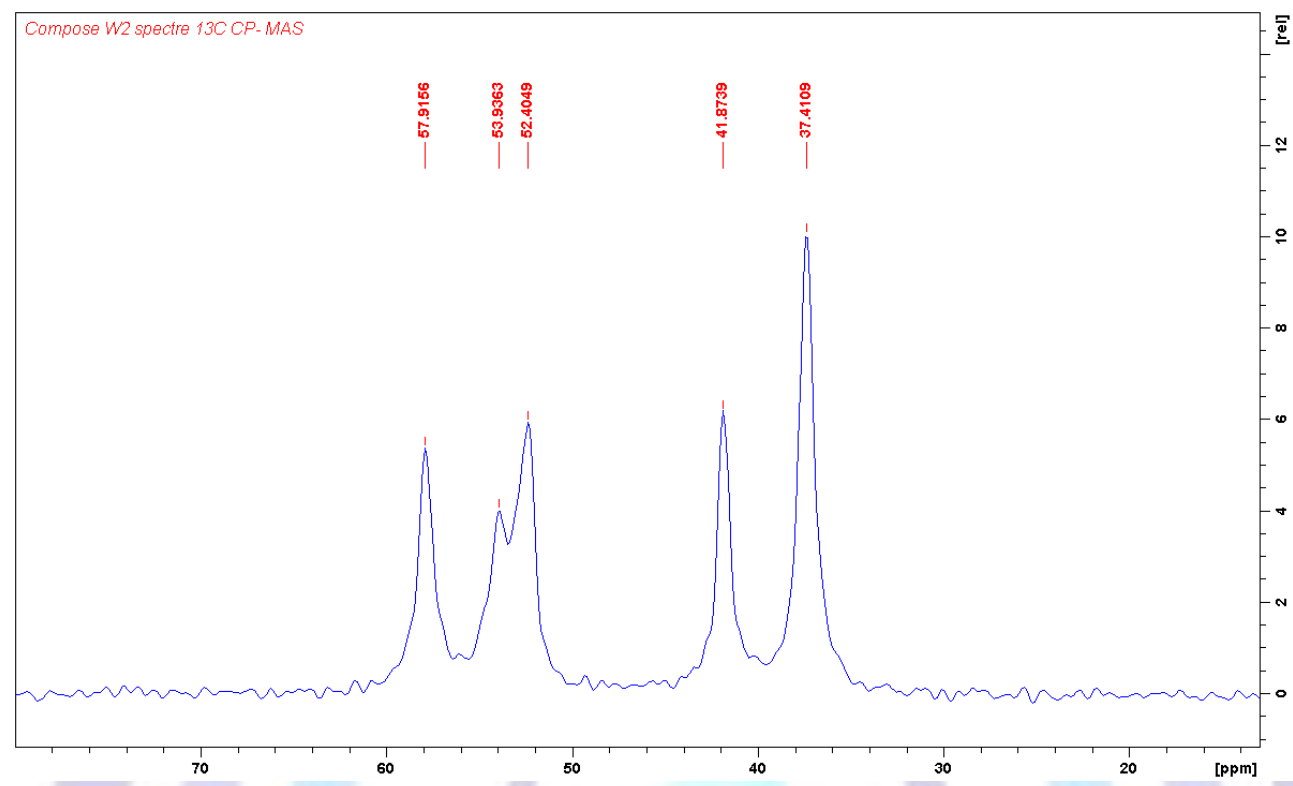

Figure $3 .{ }^{13} \mathrm{C}$ CP-MAS NMR spectrum of [CdI(C6H18N4)]l.

Table 4. Chemical shift values of the carbon atoms in $\left[\mathrm{Cdl}\left(\mathrm{C}_{6} \mathrm{H}_{18} \mathrm{~N}_{4}\right)\right]$.

\begin{tabular}{|c|c|c|c|c|}
\hline Atoms & X-rays & Full optimisation & Optimisation of protons & Experimental \\
\hline C4 & 16.9 & 39.5 & 34.8 & 37.5 \\
\hline C5 & 32.1 & 53.6 & 50.2 & 52.5 or 54 \\
\hline C6 & 19.1 & 39.3 & 36.8 & 41.9 \\
\hline C7 & 32.3 & 53.7 & 50.2 & 52.5 or 54 \\
\hline C10 & 33.3 & 53.7 & 51.1 & 58 \\
\hline C11 & 17.7 & 39.5 & 35.6 & 37.5 \\
\hline
\end{tabular}

\section{theory vs. Exp.}

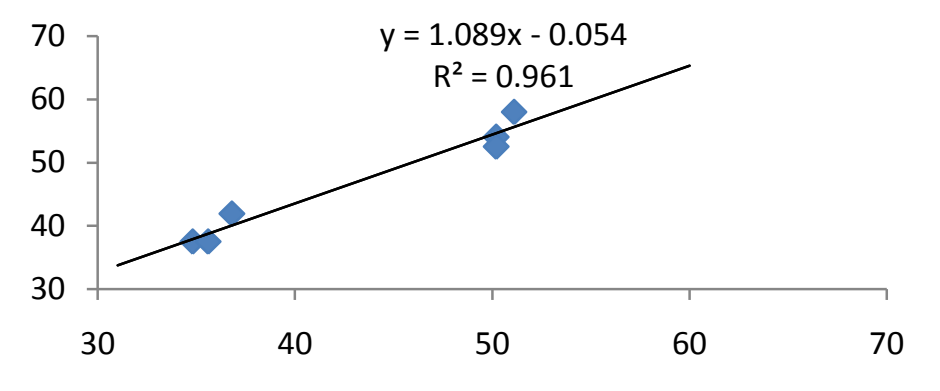

Figure 4. Comparison between experimental and calculated chemical shift values of the carbon atoms 


\subsection{IR Absorption spectroscopy}

FTIR spectroscopy was used to verify the functional groups present in the crystal and their vibrational behavior in the solid state. The IR spectrum of crystalline $\left[\mathrm{Cdl}\left(\mathrm{C}_{6} \mathrm{H}_{18} \mathrm{~N}_{4}\right)\right]$ I is shown in Figure 5. The characteristic vibrational modes of the compound can be compared to those of similar materials [29-31]. In the high-frequency region, the stretching vibrations of the amino groups can be found. Hydrogen bonding interactions are able to affect frequency as well as intensity and width of these vibrations. The bands observed at $\left(3438-3143 \mathrm{~cm}^{-1}\right)$ can be assigned to the asymmetric and symmetric stretching modes of the $\mathrm{NH}_{2}$ group. The bands between 2954 and $2803 \mathrm{~cm}^{-1}$ can be attributed to the stretching vibrations of the $\mathrm{CH}_{2}$ alkyl groups [32]. The adjacent carbon atoms attached to the $\mathrm{CH}_{2}$ groups were also involved in the wagging, twisting and rocking modes of these groups. This induces a coupling between the adjacent $\mathrm{CH}_{2} \mathrm{groups}^{-1} \mathrm{The}^{-1}$ bands observed at $\left(1399-1316 \mathrm{~cm}^{-1}\right)$ can thus be assigned to wagging modes and those observed at $\left(1286-1100 \mathrm{~cm}^{-1}\right)$ to the $\mathrm{CH}_{2}$ twisting modes and to the $\mathrm{C}-\mathrm{N}$ and $\mathrm{C}-\mathrm{C}$ stretching vibrations. Finally, those observed at $1100-730 \mathrm{~cm}^{-1}$ correspond to the $\mathrm{CH}_{2}$ rocking modes [33].

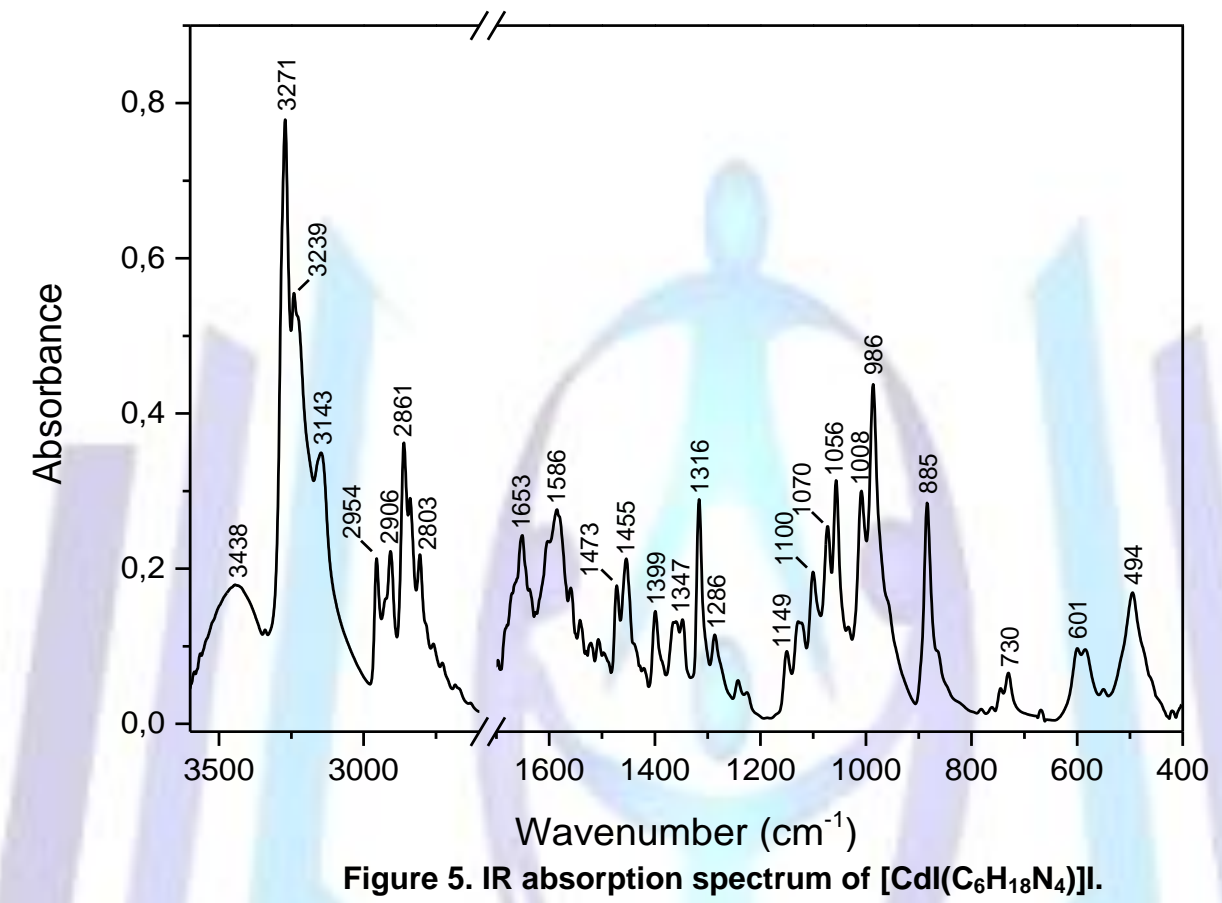

\subsection{DFT calculations}

DFT calculations were undertaken in order to comfort these attributions. They were made in the same conditions than for the NMR study. When taking the positions of all atoms as given by the X-ray diffraction study, 25 imaginary frequencies were found with values reaching $-1429 \mathrm{~cm}^{-1}$. In the case of the full optimization of all nuclei, no imaginary frequency was found but as the optimization led to a symmetric molecule the number of bands was found to be lower than that expected from the experimental study. Only the calculation where only the positions of protons were optimized led to reliable results in terms of number and positions of the bands, even if four imaginary frequencies were found but with a low value (between -77 and $-35 \mathrm{~cm}^{-1}$ ). This discrepancy is probably related to both the errors in the positions of the atoms in the X-ray determination and to the fact that the surrounding of the Cd complex was not taken into account. The resulting calculated IR spectrum is shown on Figure 6 and is similar to the experimental spectrum allowing a good correlation between the experimental and theoretical data as shown on Figure 7. Thus, the precision is well-sufficient to assign the experimental frequencies and to confirm the attributions proposed above. 


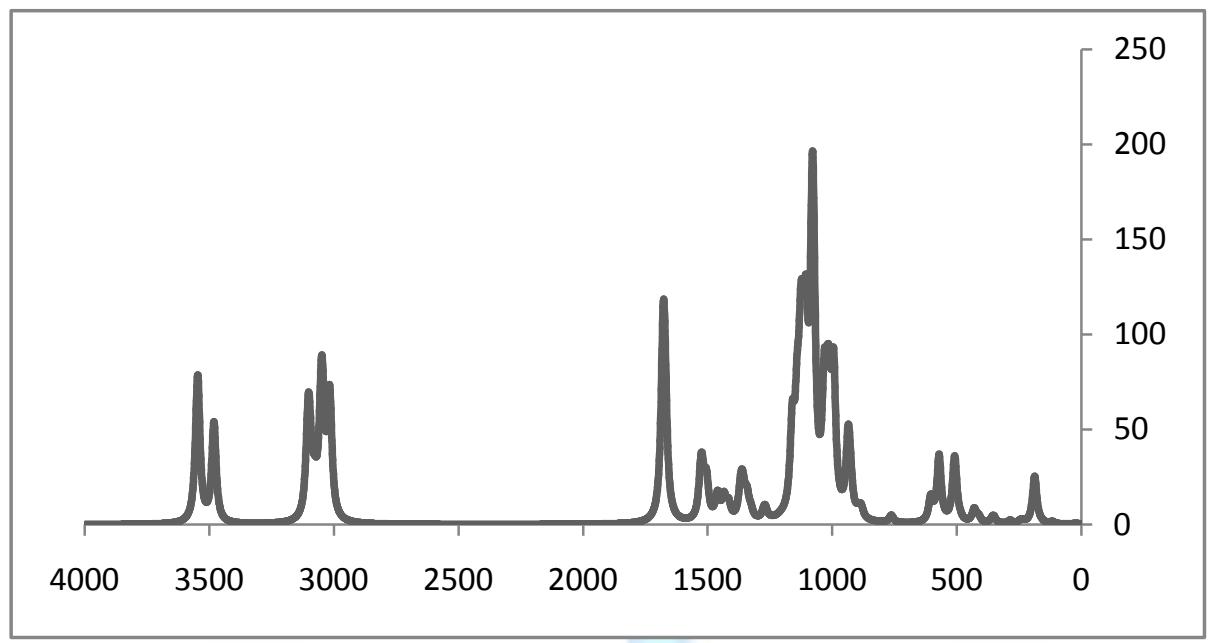

Figure 6. Calculated IR absorption spectrum after optimization of protons of $\left[\mathrm{Cdl}\left(\mathrm{C}_{6} \mathrm{H}_{18} \mathrm{~N}_{4}\right)\right]$ l.

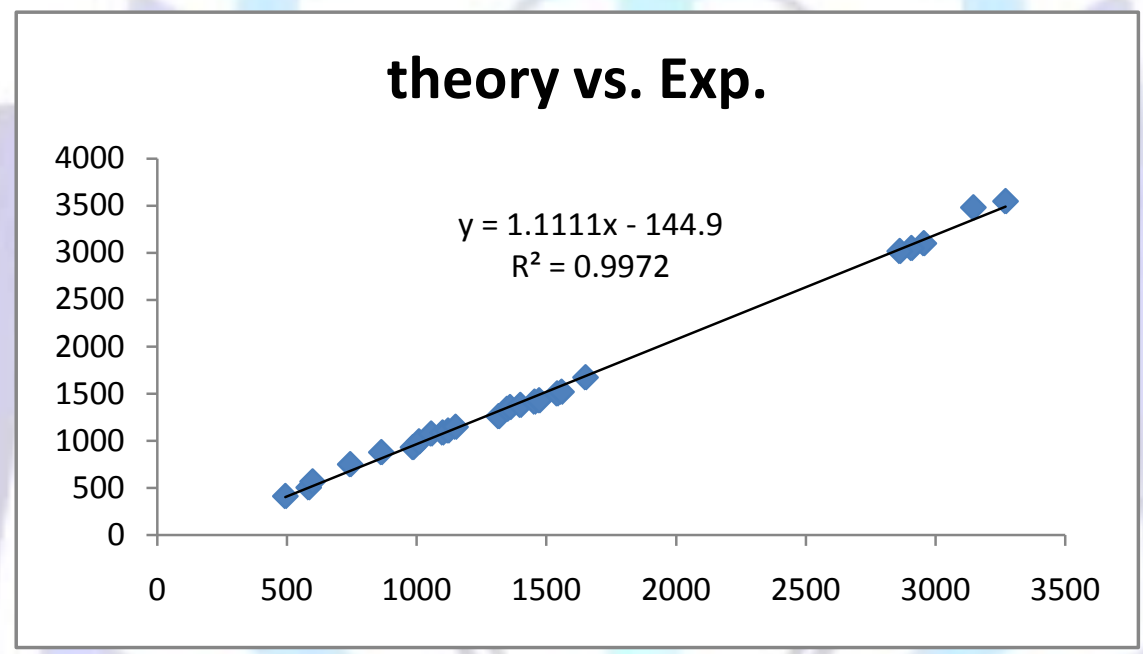

Figure 7. Comparison between experimental and calculated IR frequencies.

\section{Conclusions}

A new cadmium(II) iodide compound in combination with a tripodal amine has been prepared. It contains a pentacoordinated cadmium(II) iodide cationic complex and an iodide anion ensuring the charge balance. In the title compound, the tris(2-aminoethyl)amine, $\mathrm{L}$, behaves as a tetradentate ligand and the metal center adopts a trigonal bipyramidal geometry with lower coordination number. The presence of a bulky iodite ligand may be one of the major reasons that enforce lower coordination of this large-sized 4d ion. In the structure, the uncoordinated iodide ions are triple hydrogen bond acceptors. They connect the cationic complexes $\left[\mathrm{Cd}(\mathrm{L}) \mathrm{I}^{+}\right.$to form layers parallel to the $(\mathrm{a}, \mathrm{c})$ plane. The number of ${ }^{13} \mathrm{C}$ CP-MAS NMR lines is in full agreement with the crystallographic data. The vibrational absorption bands are identified by infrared spectroscopy and theoretical calculations.

\section{Supplementary data}

CCDC 1018181 contains the supplementary crystallographic data for the title complex. These data can be obtained free of charge from the Cambridge Crystallographic Data Centre via http://www.ccdc.cam.ac.uk/conts/retrieving.html, or from the CCDC, 12Union Road, Cambridge, CB2 1EZ, UK: fax: (+44) 01223-336-033; e-mail: deposit@ccdc.cam.ac.

\section{Acknowledgments}

We would like to acknowledge the support provided by the Secretary of State for Scientific Research and Technology of Tunisia. 


\section{References}

[1] Ye B. H., Tong M. L., Chen X. M., Coord. Chem. Rev. 249 (2005) 545.

[2] Rosi N. L, Kim J., Eddaoudi M., Chen B., O’Keeffe M., Yaghi O. M., J. Am. Chem. Soc. 127 (2005) 1504.

[3] MacGillivray L. R., Papaefstathiou G. S., Friscic T., Hamilton T. D., Bucar D. K., Chu Q., Varshney D. B., Georgiev I. G., Acc. Chem. Res. 4 (2008) 280.

[4] Habib H. A., Hoffmann A., Hoppe H A., Steinfeld G., Janiak C., Inorg. Chem. 48 (2009) 2166.

[5] Marder S. R., Bruce D. W., O'Hare D. (eds) Metal containing materials for nonlinear optics in inorganic materials, 2nd edn. Wiley, Chichester (1996).

[6] Special issue on molecular materials in electronic and optoelectronic Devices, Acc. Chem. Res. 32 (1999) 191.

[7] Petty M., Molecular electronics: from principles to practice. Wiley, Chichester (2008).

[8] Shyu E., Supkowski R. M., La Duca R. L., Inorg. Chem. 48 (2009) 2723.

[9] Luan X. J., Wang Y.-Y., Li D.-S., Liu P., Hu H.-M., Shi Q.-Z., Peng S.-M., Angew. Chem. Int. Ed. 44 (2005) 3864.

[10] Chan W.; K., Coord. Chem. Rev. 251 (2007) 2104.

[11] Vigato P. A., Tamburini S., Coord. Chem. Rev. 252 (2008) 1871.

[12] Lodeiro C., Pina F., Coord. Chem. Rev. 253 (2009) 1353.

[13] Satapathi S., Roy S., Bhar K., Ghosh R., Rao A. S., Ghosh B. K., Struct. Chem. 22 (2011) 605.

[14] Otwinowski Z., Minor W., Methods in Enzymology, Macromolecular Crystallography, Carter Jr C. W. \& Sweet R. M. Eds., New York: Academic Press, Part A. 276 (1997) 307.

[15] Blessing R. H., Acta Crystallogr., A51 (1995) 33.

[16] Altomare A., Burla M. C., Camalli M., Cascarano G., Giacovazzo C., Guagliardi A., Moliterni A. G., Polidori G., Spagna R., J. Appl. Crystallogr. 32 (1999) 115-119;

[17] Sheldrick, G.M. SHELX97, Program for Crystal Structure Refinement. University of Göttingen, Göttingen, Germany, 1997.

[18] Farrugia L. J., J. Appl. Crystallogr. 32 (1999) 837.

[19] Burnett M. N., Johnson C.K., ORTEPIII. Report ORNL-6895. Oak Ridge National Laboratory, Oak Ridge, Tennessee, USA, 1996.

[20] Brandenburg K., DIAMOND version 2.0, 1998.

[21] Addison A. W., Nageswara R. T., Reedijk J., Rijn J., Verschoor G. J., Chem. Soc. Dalton Trans. (1984) 1349.

[22] Zhang H., Cai J., Feng X.-L., Sang H.-Y, Liu J.-Z., Li X.-Y., Ji L.-N., Polyhedron 21 (2002) 721.

[23] Xu T.-T., Xu X.-Y., Gao J., Ni S.-S., Wang D.-Q., Yang X.-J., Lu L.-D., Xu G.-X., Chin. J. Inorg. Chem. 23 (2007) 128.

[24] Das S., Bhar K., Fun H.-K., Chantrapromma S., Ghosh B.K., Inorg. Chim. Acta 363 (2010) 784.

[25] Yuan H. Q., Aoki K., Fujisawa I., Inorg. Chim. Acta 362 (2009) 975.

[26] Zhang Z.-M., Gao J., Xu T.-T., Wang D.-Q. Acta Crystallogr., Sect.E 62 (2006), m3245.

[27] Salam Md. A., Yuan H. Q., Kikuchi T., Prasad N. A., Fujisawa I., Aoki K., Inorg. Chim. Acta 362 (2009) 1158.

[28] Wills A.S., VaList, Program available from www.ccp14.ac.uk

[29] Belhouchet M., Bahri M., Savariault J. M., Mhiri T., Spectrochim. Acta A 61 (2005) 387.

[30] Calve N. L., Romain F., Limage M. H., Novak A., J. Mol. Struct. 200 (1989) 131.

[31] Shanmuga Sundara Raj S., Fun H. K., Zhao P. S., Jian F. F., Lu L. D., Yang X. J., Wang, X., Acta Crystallogr. C56 (2000) 742.

[32] Chenon B., Sandorfy C., Can. J. Chem. 36 (1958) 1181.

[33] Nakamoto K., Infrared and Raman Spectra of Inorganic and Coordination Compounds, Wiley-Interscience, New York, 1986. 